\title{
Caveolin-1 regulates cancer cell metabolism via scavenging Nrf2 and suppressing MnSOD-driven glycolysis
}

\author{
Peter C. Hart', ${ }^{1,2}$ Bianca A. Ratti, ${ }^{1,7}$, Mao Mao ${ }^{1}$, Kristine Ansenberger-Fricano ${ }^{1}$, Ayesha \\ N. Shajahan-Haq ${ }^{6}$, Angela L. Tyner ${ }^{3}$, Richard D. Minshall ${ }^{4,5}$, Marcelo G. Bonini ${ }^{1,2,4,7}$ \\ ${ }^{1}$ Department of Medicine, University of Illinois College of Medicine at Chicago, Chicago, IL, USA \\ ${ }^{2}$ Department of Pathology, University of Illinois College of Medicine at Chicago, Chicago, IL, USA \\ ${ }^{3}$ Department of Biochemistry and Molecular Genetics, University of Illinois College of Medicine at Chicago, Chicago, IL, USA \\ ${ }^{4}$ Department of Pharmacology, University of Illinois College of Medicine at Chicago, Chicago, IL, USA \\ ${ }^{5}$ Department of Anesthesiology, University of Illinois College of Medicine at Chicago, Chicago, IL, USA \\ ${ }^{6}$ Department of Oncology, Georgetown University, Medical Center, Washington, D.C., USA \\ ${ }^{7}$ Programa de Biociencias Aplicadas a Farmacia (PBF) Universidade Estadual de Maringa, Maringa, PR, Brazil \\ Correspondence to: \\ Marcelo G. Bonini, e-mail: mbonini@uic.edu \\ Keywords: Caveolin-1, MnSOD, Nrf2, breast cancer, tumor progression
}

Received: March 10, $2015 \quad$ Accepted: October 16, $2015 \quad$ Published: October 26, 2015

\section{ABSTRACT}

Aerobic glycolysis is an indispensable component of aggressive cancer cell metabolism. It also distinguishes cancer cells from most healthy cell types in the body. Particularly for this reason, targeting the metabolism to improve treatment outcomes has long been perceived as a potentially valuable strategy. In practice, however, our limited knowledge of why and how metabolic reprogramming occurs has prevented progress towards therapeutic interventions that exploit the metabolic peculiarities of tumors. We recently described that in breast cancer, MnSOD upregulation is both necessary and sufficient to activate glycolysis. Here, we focused on determining the molecular mechanisms of MnSOD upregulation. We found that Caveolin-1 (Cav-1) is a central component of this mechanism due to its suppressive effects of NF-E2related factor 2 ( Nrf2), a transcription factor upstream of MnSOD. In transformed MCF10A(Er/Src) cells, Cav-1 loss preceded the activation of Nrf2 and its induction of MnSOD expression. Consistently, with previous observations, MnSOD expression secondary to Nrf2 activation led to an increase in the glycolytic rate dependent on $\mathrm{mtH}_{2} \mathrm{O}_{2}$ production and the activation of AMPK. Moreover, rescue of Cav-1 expression in a breast cancer cell line (MCF7) suppressed Nrf2 and reduced MnSOD expression. Experimental data were reinforced by epidemiologic nested case-control studies showing that Cav-1 and MnSOD are inversely expressed in cases of invasive ductal carcinoma, with low Cav-1 and high MnSOD expression being associated with lower 5-year survival rates and molecular subtypes with poorest prognosis.

\section{INTRODUCTION}

Caveolin-1 (Cav-1) is a scaffold protein primarily located at the lipid raft domains in the cellular plasma membrane. The roles of Cav-1 as a facilitator of endocytosis, transcytosis, and trafficking of cholesterol have long been acknowledged [1-4]. More recently, however, Cav-1 function as an active regulator of cell signaling has become better appreciated. By defining niches where signals are generated at restricted microdomains $[3,5,6]$ or directly regulating the activity of nuclear factors [7-9] and receptors [3, 5], Cav-1 forms a molecular platform modulating a variety of signaling programs that regulate cellular responses to environmental cues $[6,10]$. Noteworthy, Cav-1 expression has been reported to vary in response to toxic exposures [11-13], during cellular differentiation and migration $[14,15]$ and under conditions of elevated reactive oxygen species (ROS) and reactive nitrogen species (RNS) production [16-18]. Data from other groups have indicated that 
loss of Cav-1 acutely accentuates the production of $\mathrm{H}_{2} \mathrm{O}_{2}$ and promotes oxidative stress [19, 20]. When persistent, suppression of Cav-1 expression appears to promote the emergence of pathogenic phenotypes $[16,19,21]$ characterized by a stronger reliance on glycolytic metabolism [19, 22] and active cellular proliferation [23-25]. It is, however, unclear how variations in Cav-1 expression translate into robust changes in cellular metabolism, particularly in the case of cancer cells.

Here, we demonstrate that the reconstitution of Cav-1 expression in invasive MCF7 breast ductal carcinoma cells that are normally deficient in Cav-1 suppresses glycolysis and enhances mitochondria-dependent ATP production. These effects were largely dependent on the suppression of Nrf2-driven upregulation of MnSOD which, as previously shown [26], is required and sufficient for the glycolytic switch. Moreover, we found strong correlations between tumor grade, tumor stage, and 5-year breast cancer survival with Cav-1 expression level, with low Cav-1 expression being associated with higher tumor grade and lower 5-year survival. These observations indicate that perhaps low levels of Cav-1 expression distinguish a subgroup of aggressive breast cancers with strong reliance on glycolytic metabolism.

\section{RESULTS}

\section{Cav-1 and MnSOD are inversely expressed in human breast cancer and predict risk of aggressive phenotypes}

A nested case-control study of existing data by Sorlie et al. (Figure 1A-1F, [27]) and Curtis et al. (Figure $1 \mathrm{G}$ and $1 \mathrm{H},[28]$ ) showed that Cav-1 mRNA is markedly reduced in cancerous breast tissue as compared to healthy controls. Cav-1 expression was markedly reduced in invasive ductal carcinoma (Figure 1A-1C) and observed to progressively correlate in a grade- and stage-dependent manner (Figure 1B and 1C, respectively). Noteworthy, robust suppression of Cav-1 gene expression was observed between the first stage of malignancy (grade 1 and T1) and normal tissue. Within the examined cohort, it was also observed that MnSOD mRNA expression was significantly increased in invasive breast cancer (Figure 1D). Importantly, stratification of this population by either decreasing Cav-1 or increasing MnSOD expression showed that lower Cav-1 (and higher MnSOD) indicated a significant increase in mortality (Figure 1E and 1F, respectively). Interestingly, Cav-1 and MnSOD had a moderate negative correlation (Pearson's $R=-0.51, p<0.001$ ) in patients with invasive breast cancer (Figure $1 \mathrm{G}$ ), and stratification of this cohort by low Cav-1 and high MnSOD expression in invasive ductal carcinoma indicated increased mortality (odds ratio, $\mathrm{OR}=1.576,95 \% \mathrm{CI} 1.076-2.307, p<0.05$ ) and conferred risk of aggressive disease $(\mathrm{OR}=2.099$, $95 \%$ CI $1.321-3.333, p<0.005)$, as shown in Table 1 . The analysis of available data also indicated that the expression level of Cav-1 and MnSOD in human breast cancer has weak negative prognostic value independently, but in combination, the Cav-1 $1^{\text {low }} / \mathrm{MnSOD}^{\text {high }}$ signature is strongly correlated with more aggressive forms of the disease. In contrast, stratification of this cohort by high Cav-1 and low MnSOD conferred a two-fold lower risk of death from the disease $(\mathrm{OR}=0.545,95 \%$ CI $0.354-$ $0.839, p<0.01$ ), and sufficiently discriminated between healthy subjects and patients with invasive ductal carcinoma $(\mathrm{OR}=0.203,95 \%$ CI $0.127-0.324, p<0.01$, Table 2), together indicating that this molecular fingerprint may have prognostic value for risk stratification. This notion was reinforced by a separate study from Kao et al. [29] showing that the Cav-1 ${ }^{\text {low }} / \mathrm{MnSOD}^{\text {high }}$ phenotype had a higher mean survival time of 4.6 compared to 3.9 years in the reference group (Figure $1 \mathrm{H}$ ). Taken together, the relationship between Cav-1 and MnSOD appears to have predictive value indicating more invasive forms of breast cancer.

\section{The expression of Cav-1 and Nrf2 are inversely associated in human breast cancer}

Findings of epidemiologic associations between levels of Cav-1 and MnSOD expression and breast cancer outcome led us to perform a set of prospective studies using a tissue microarray containing 36 breast cancer cases and 12 normal tissue controls stratified by histologic grade and clinical stage (TMA-1005, Protein Biotechnologies, Ramona, CA) to detect correlations between Cav-1/MnSOD phenotypes and clinical grade and stage. Figure 2A, 2B summarizes our findings that Cav-1 expression is progressively reduced in ductal epithelial cells by increasing histologic grade and clinical stage. Cav-1 was previously shown to bind and suppress NF-E2-related factor 2 (Nrf2), a nuclear factor upstream of MnSOD expression [8, 30]. Consistent with these findings by other groups, we observed a clear inverse relationship between $\mathrm{Cav}-1$ and Nrf2 expression especially in higher grade (II-III) tumors.

\section{Cav-1 expression in MCF7 breast cancer epithelial cells represses Nrf2 and MnSOD}

Findings reported above indicated that Cav-1 could potentially restrict MnSOD expression via its negative regulation of Nrf2 activity in breast cancer. In a luminal breast cancer epithelial cell line devoid of Cav-1 (MCF7) we ectopically expressed Cav-1. Restoration of Cav-1 was sufficient to repress $\mathrm{Nrf} 2$ and, as anticipated, to suppress MnSOD expression (Figure 3A), indicating that Cav-1 indirectly regulates MnSOD expression by controlling Nrf2. Suppression of 
A.

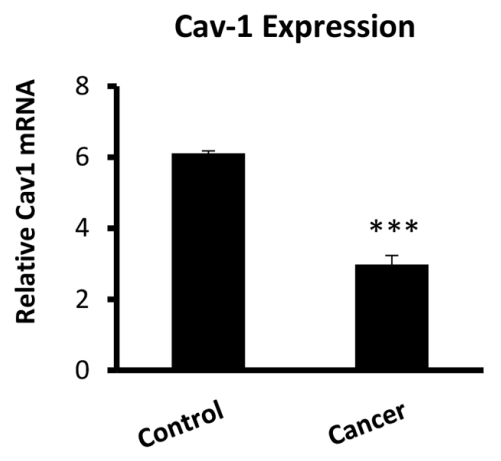

D.

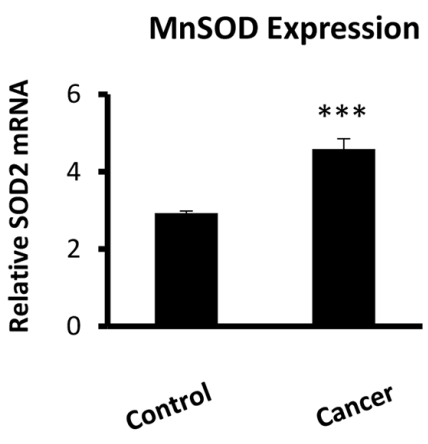

B.

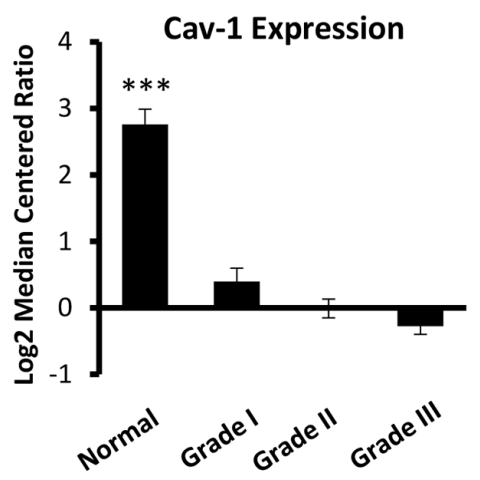

E.

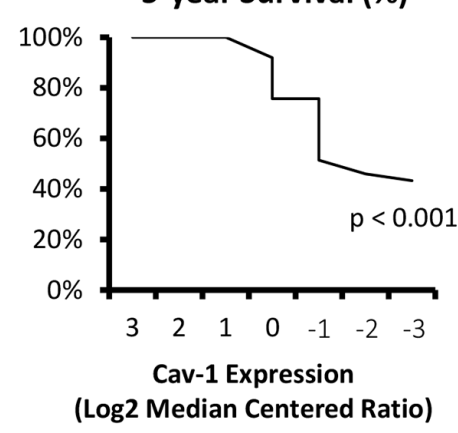

C.

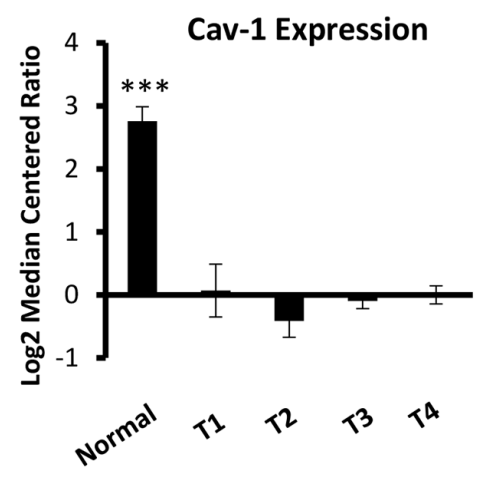

F.

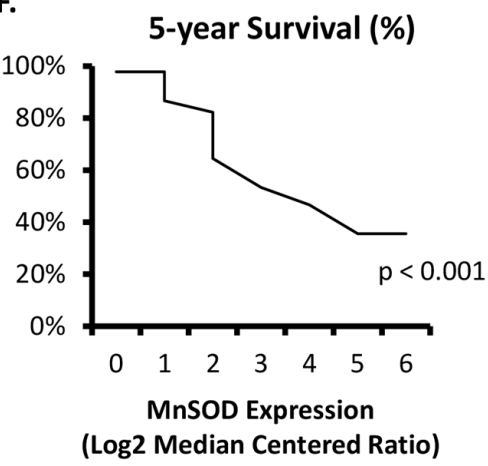

G.

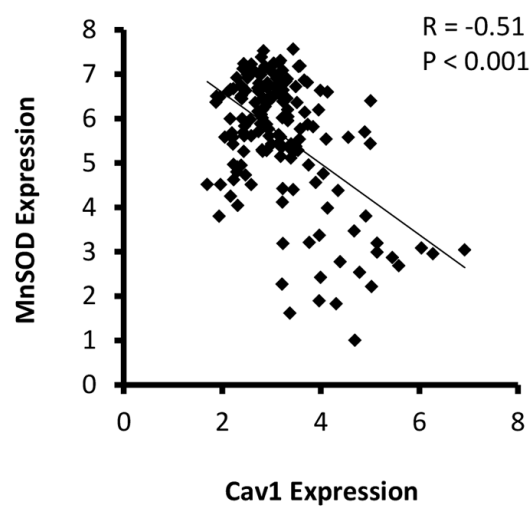

H.

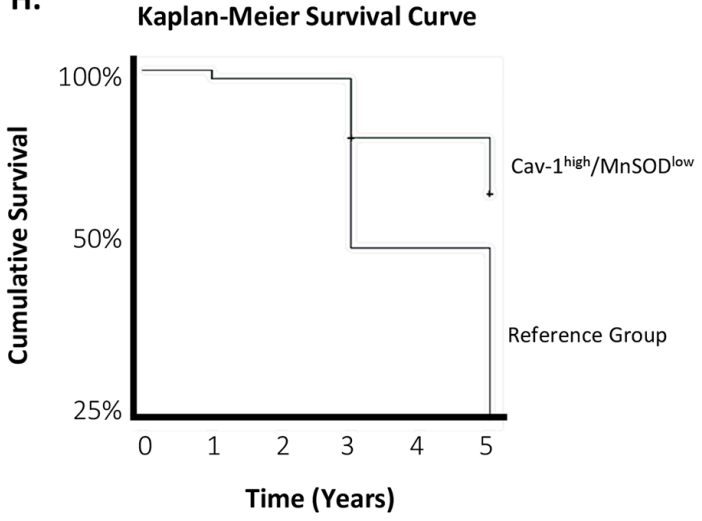

Figure 1: Cav-1 and MnSOD mRNA levels are inversely expressed in human breast cancer patients. Nested case-control studies were performed on data previously obtained by Sorlie [27](Figure 1A-1F) and Curtis [28](Figure 1G and 1H). Cav-1 and MnSOD mRNA expression obtained from a primary site is expressed as $\log 2$ median centered ratio for case (invasive ductal carcinoma) and control (normal breast tissue) subjects. A. Cav-1 mRNA expression between controls and all cases with IDC $(N=116)$. B. Cav-1 mRNA expression stratified by grade $(N=116)$. C. Cav-1 mRNA expression stratified by tumor size $(\mathrm{T})(N=116)$. D. MnSOD mRNA expression between controls and all cases with IDC $(N=116)$. E. Cohort is stratified using Cav-1 mRNA expression set as the continuous variable to determine Cav-1-dependent survival curve $(N=116)$. Comparison between highest and lowest Cav-1 mRNA expression demonstrated a significant reduction in survival in patients with lowest Cav-1, as assessed by Pearson's Chi-Square Test. F. Cohort is stratified using MnSOD mRNA expression set as the continuous variable to determine MnSOD-dependent survival curve $(N=116)$. In contrast to Figure $1 \mathrm{E}$, analysis between lowest and highest MnSOD mRNA expression showed a marked increase in mortality in patients with highest MnSOD, as determined by Pearson's Chi-Square Test. G. Correlation plot of Cav-1 and MnSOD expression demonstrating a moderate inverse/negative correlation of Cav-1 and MnSOD in patients with aggressive invasive ductal carcinoma (e.g., medullary carcinoma). H. Kaplan-Meier survival estimate curve in patients stratified by high Cav-1 (quartile 4) paired with low MnSOD (quartile 1) compared to the reference group using data obtained previously by Kao [29]. (One-way ANOVA with post-hoc two-sided $t$-test, ${ }^{*} * *=p<0.001$; Student's two-sided $t$-test, ${ }^{* * *}=p 0.001$;). 
Table 1: Stratification of patients with invasive ductal carcinoma by $\mathrm{Cav}^{\mathrm{l}}{ }^{\text {low }}$ and $\mathrm{MnSOD}{ }^{\text {high }}$

\begin{tabular}{|l|c|c|}
\hline \multicolumn{2}{|c|}{ Basal Phenotype } & Mortality \\
\hline Reference Group (\%) & $181(1.61)$ & $669(5.86)$ \\
\hline Cases [Cav-1 $\mathbf{I}^{\text {low }} / \mathbf{M n S O D}^{\text {high }}$ (\%) & $26(22)$ & $61(53)$ \\
\hline Odds Ratio & 2.099 & 1.576 \\
\hline CI 95\% & $1.321-3.333$ & $1.076-2.307$ \\
\hline p value & $p<0.05$ & $p<0.05$ \\
\hline
\end{tabular}

Table 2: Stratification of patients with invasive ductal carcinoma by Cav-1 ${ }^{\text {high }}$ and MnSOD ${ }^{\text {low }}$

\begin{tabular}{|l|c|c|}
\hline \multicolumn{2}{|c|}{ IDC } & Mortality \\
\hline Reference Group (\%) & $1480(92)$ & $699(43)$ \\
\hline Cases /Cav-1 ${ }^{\text {high }} / \mathbf{M n S O D}{ }^{\text {low }}$ (\%) & $75(72)$ & $31(1.9)$ \\
\hline Odds Ratio & 0.203 & 0.545 \\
\hline CI 95\% & $0.127-0.324$ & $0.354-0.839$ \\
\hline p value & $p<0.01$ & $p<0.01$ \\
\hline
\end{tabular}

MnSOD expression by Cav-1 markedly reduced steady state levels of $\mathrm{H}_{2} \mathrm{O}_{2}$ (Figure 3B). This result could be explained, in part, by the detection of increased expression of antioxidant enzymes (glutathione peroxidase 1, GPx-1, and thioredoxin reductase (TXNRD3)) responsible for the clearance of $\mathrm{H}_{2} \mathrm{O}_{2}$ in Cav-1 reconstituted cells (Supplementary Figure $\mathrm{S} 1$ ). The reduction in steady state $\mathrm{H}_{2} \mathrm{O}_{2}$ levels in Cav-1 reconstituted MCF7 cells occurred in parallel to a clearly detectable reduction in the oxidation of Nrf2 negative regulator, Kelch-like ECH-associated protein 1 (Keap1), as determined by the labeling of Keap1-sulfenic acid derivatives with 5,5-Dimethylcyclohexane-1,3-dione (dimedone). Dimedone is a cyclic dione that reacts with protein-sulfenic acids to produce an adduct that can be immunologically detected and quantified (Figure 3C). Oxidation of Keap1 has been reported to result in the disassembly of the Keap1/Nrf2 complex, leading to Nrf2 nuclear translocation and activation as a transcription factor [31]. Cav-1 was found to form a ternary complex interacting directly with both Keap1 and Nrf2. As shown in Figure 3D, Cav-1 binding to Keap1 and Nrf2 was strongly suppressed by exogenous $\mathrm{H}_{2} \mathrm{O}_{2}$, indicating that fluctuations in the levels of $\mathrm{H}_{2} \mathrm{O}_{2}$ can simultaneously lead to the release of Nrf2/Keap1 from Cav-1 and the dissociation of Nrf2 from Keap1. The suppressive effect of Cav-1 on the accumulation of $\mathrm{Nrf} 2$ was confirmed using a NanoLuc reporter system (Nrf2-luciferase conjugated protein) by Promega (Madison, WI). We found that Cav-1 expression in MCF7 cells resulted in a reduction of $\mathrm{Nrf} 2$ accumulation which we attribute to the faster degradation of $\mathrm{Nrf2}$ in Cav-1 reconstituted MCF7 cells (Figure 3E). Lower Nrf2 stability led to reduced MnSOD protein expression, an effect that was recapitulated either by Cav-1 reconstitution or by silencing Nrf2 (Figure 3F). These results position
Nrf2 as a primary effector of MnSOD upregulation in breast cancer cells with a Cav-1 null phenotype.

\section{Reconstitution of Cav-1 suppresses MnSOD- dependent AMPK activation and AMPK-driven glycolysis in breast cancer epithelial cells}

Results shown in Figure 4A indicate that by promoting Nrf2 association with Keap1, Cav-1 prevents Nrf2 accumulation thereby suppressing MnSOD protein expression. Consistent with previous studies [26], one measurable effect of reducing MnSOD protein expression was the deactivation of AMPK as indicated by a reduction in phosphorylation of the AMPK activation site Thr172 (Figure 4B). Suppression of AMPK phosphorylation resulted in an increase in mitochondrial electrochemical potential (Figure 4C), an enhancement in the steady state levels of ATP (Figure 4D), and an increase in OCR/ ECAR indicating a shift towards aerobic respiration (Figure 4E). The dampening of AMPK activation also resulted in inhibition of phosphofructokinase 2 (PFK2) activation, a rate limiting enzyme in the glycolytic pathway positively regulated by AMPK (Supplementary Figure S2). Consistent with these observations, we also found that glycolysis is suppressed in Cav-1 reconstituted cells (Figure 4F). The effects of Cav-1 in MCF7 cells could be reversed by the ectopic expression of MnSOD by adenoviral transfection (Supplementary Figure S3A). This result indicates that the increase in MnSOD expression that results in increased $\mathrm{H}_{2} \mathrm{O}_{2}$ production and the activation of glycolysis is secondary to the loss of Cav-1 expression (Supplementary Figure S3B). Mechanistically, it was also found that, consistent with previous findings [26], AMPK is activated by $\mathrm{H}_{2} \mathrm{O}_{2}$ originating from the mitochondria 
A.

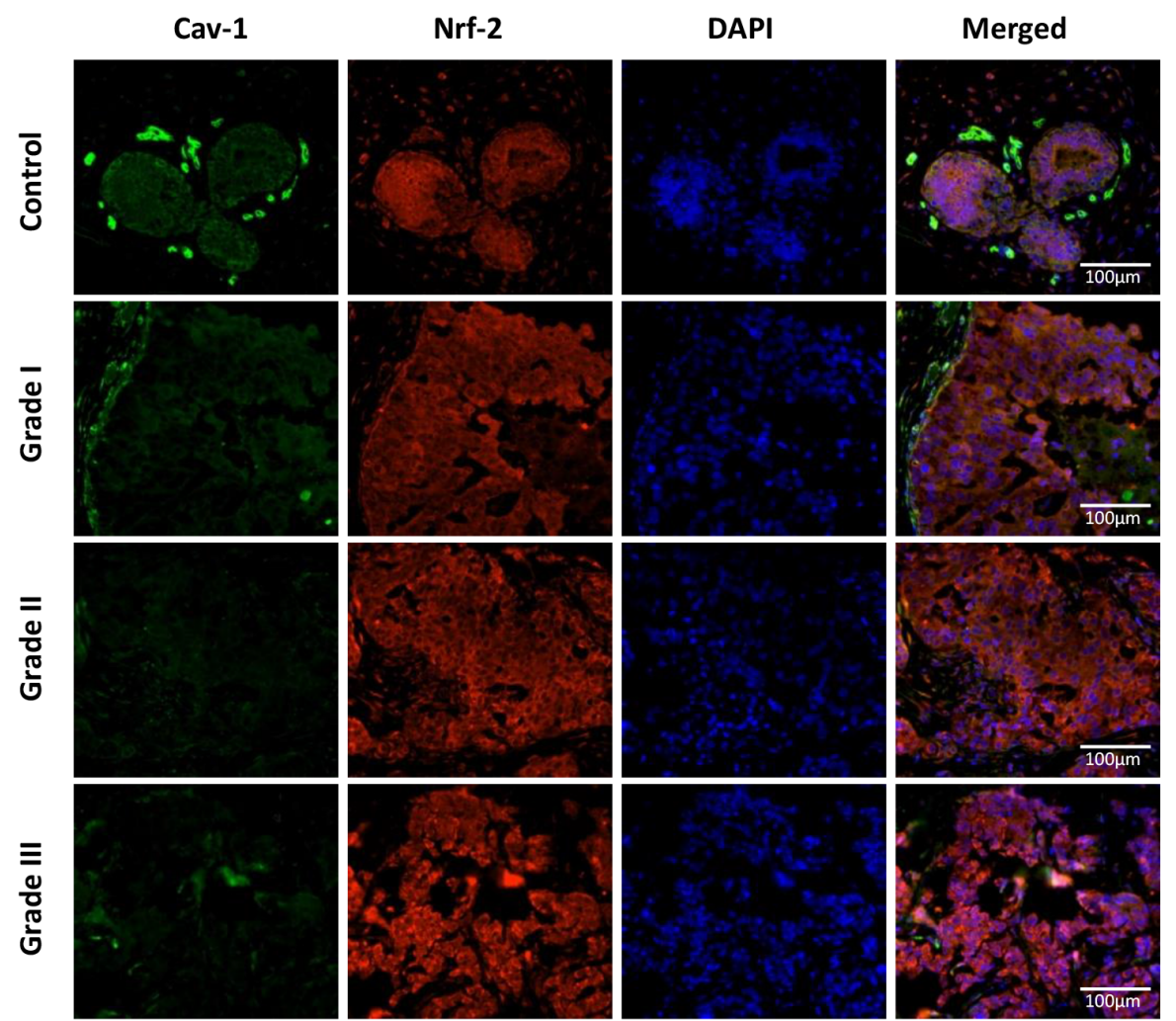

B.

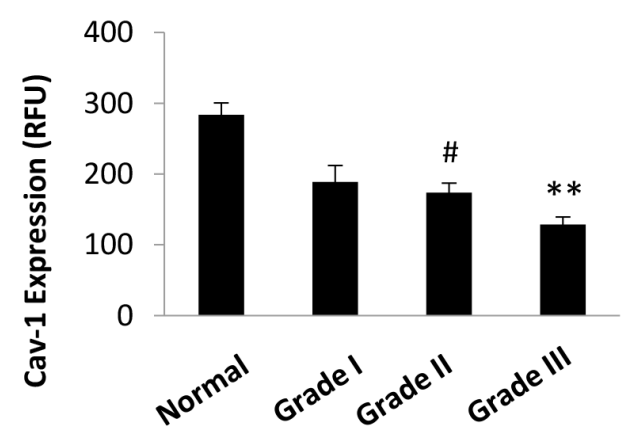

Nrf-2

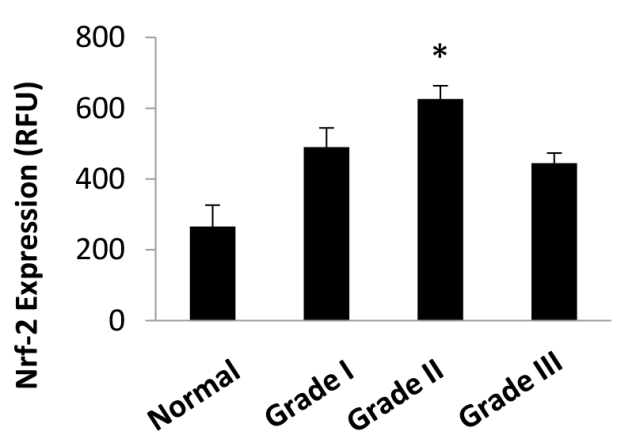

Figure 2: Cav-1 and Nrf2 protein expression are inversely associated in human breast cancer tissue. A. Cav-1 (green) and $\mathrm{Nrf2}$ (red) protein expression in invasive ductal carcinoma tissue obtained from TMA-1005 (Protein Biotechnologies). B. Representative images were selected by identifying images with closest measurements to that of the mean derived for each grade. (One-way ANOVA with post-hoc two-sided $t$-test, $* *=p<0.005, * * *=p<0.001)$.

since the transfection of a mitochondria-targeted catalase (mt-catalase) that prevents the efflux of $\mathrm{H}_{2} \mathrm{O}_{2}$ from mitochondria, reduced both AMPK activation (Figure 4G) and glycolysis (Figure 4H). Consistent with the hypothesis that loss of Cav-1 expression promotes more aggressive cancer phenotypes, rescue of Cav-1 expression in MCF7 cells led to a marked inhibition of anchorage-independent growth as determined by a reduction in colony formation in soft agar (Figure 4I). Overall, these results indicate that Cav-1 expression suppresses MnSOD-dependent glycolysis and anoikis that characterize more aggressive cancer phenotypes.

\section{Cav-1 loss during malignant transformation leads to Nrf2-driven MnSOD upregulation}

Using a model of inducible transformation, we tested the concept that loss of Cav-1 during the transition 
A.

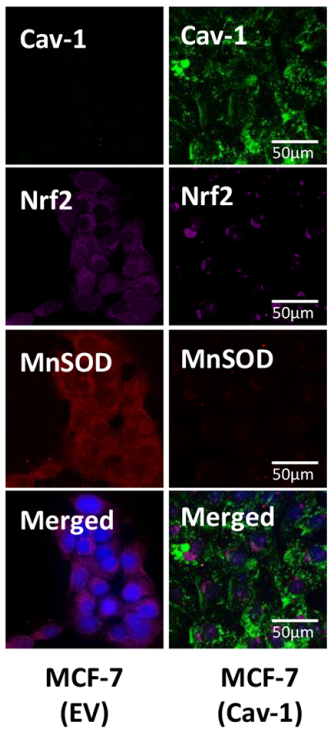

B.

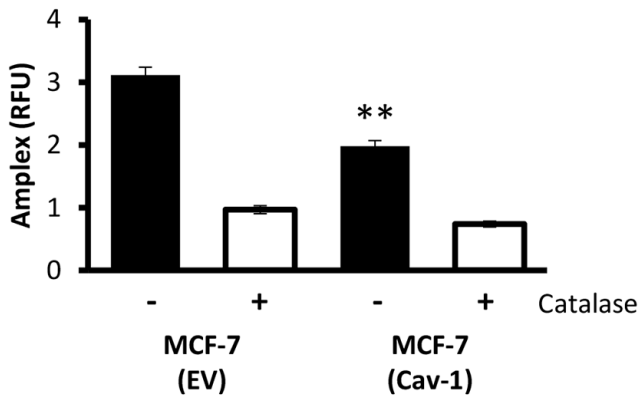

c.

\section{IP: Keap1}

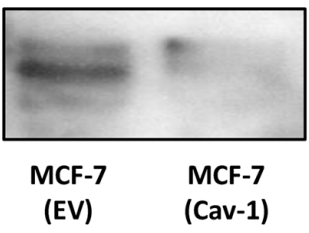

IB: Dimedone

D.

IP: Nrf-2

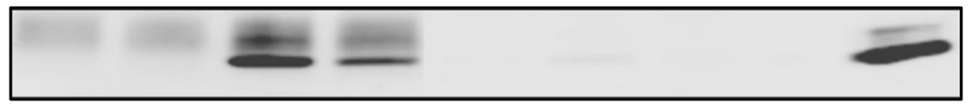

IB: Cav-1

IP: Keap1

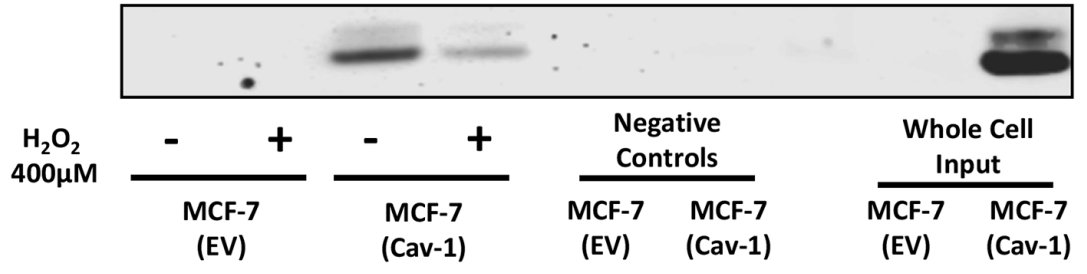

IB: Cav-1

E.

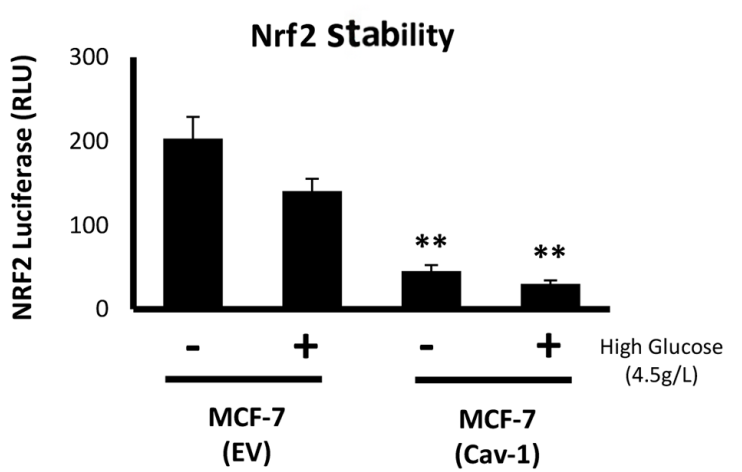

F.

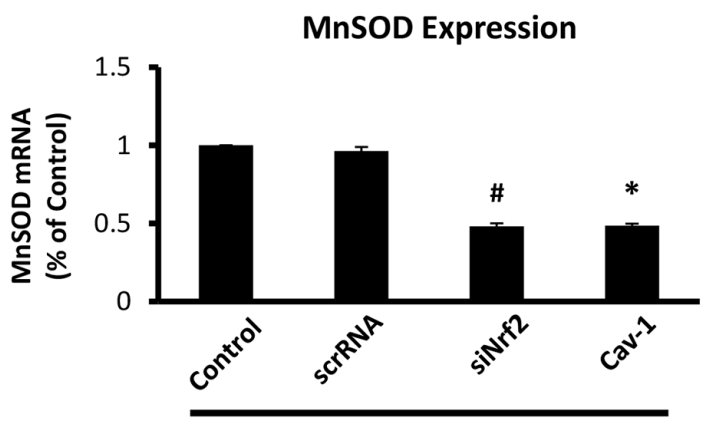

MCF-7

Figure 3: Cav-1 prevents MnSOD upregulation by repression of Nrf2. A. Cav-1 (green) transfected MCF7 cells demonstrate a reduction of $\mathrm{Nrf2}$ (purple) and MnSOD (red). $\mathbf{B}$. $\mathrm{H}_{2} \mathrm{O}_{2}$ production in MCF7 cells expressing Cav-1 is reduced when compared to MCF7 cells devoid of Cav-1. $\mathrm{H}_{2} \mathrm{O}_{2}$ was measured as described in methods. C. Cysteine sulfenic acid formation in MCF7 empty vector and Cav-1 expression cells using dimedone in combination with immunoprecipitation of Keap1 shows a reduction in Keap1 thiol oxidation in Cav-1 expressing MCF7 cells. D. Immunoprecipitation of Nrf2 (top) and Keap1 (bottom) demonstrates direct interactions of both proteins to Cav-1. Cells were treated with $400 \mu \mathrm{M} \mathrm{H}_{2} \mathrm{O}_{2}$ for $1 \mathrm{~h}$ prior to preparation of lysates for immunoprecipitation as described in methods. E. Nrf-2 transcriptional activity was indirectly determined using NanoLuc Nrf2-stability luciferase reporter assay in MCF7 cells with and without Cav-1 stable expression in both DMEM:F12 and DMEM high glucose (4.5g/L) conditions. F. MnSOD mRNA expression following Cav-1 ectopic expression or silencing of Nrf2 in MCF7 cells shows a similar reduction in MnSOD mRNA. (Student's two-sided $t$-test, \# $p=0.06,{ }^{*}=p<0.05$ ). 
A.

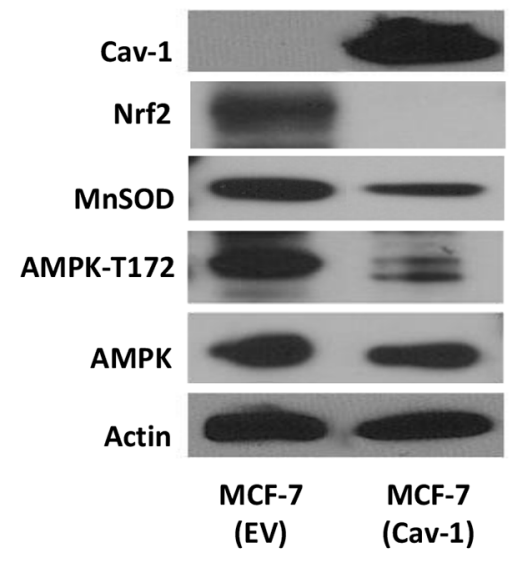

D.

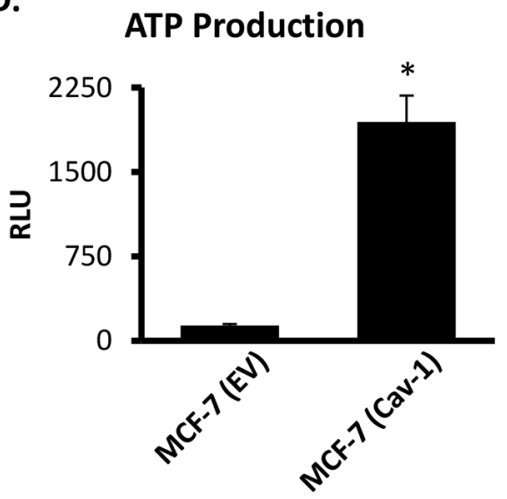

G.

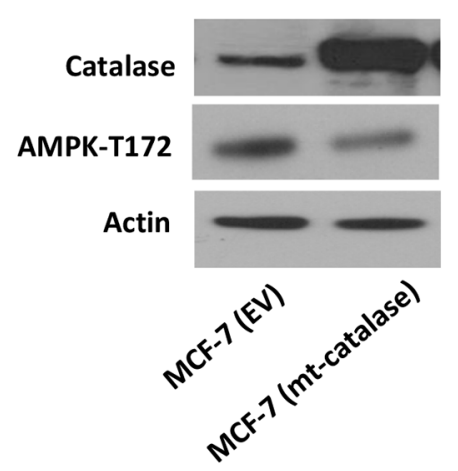

B.

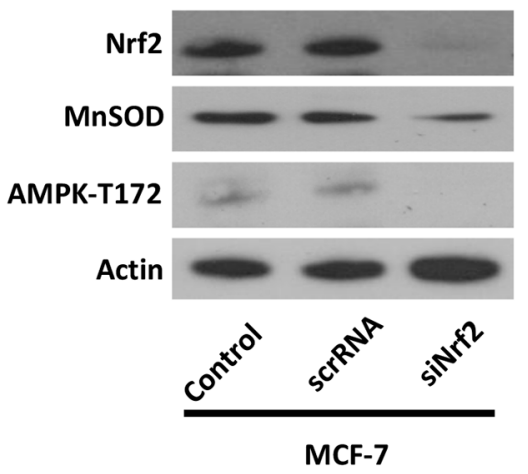

E. Oxidative Phosphorylation

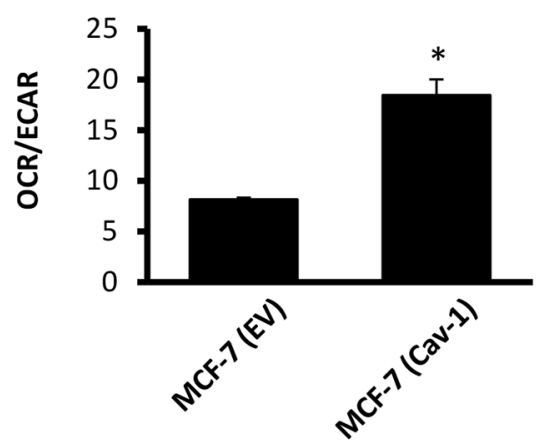

H.

Glycolysis

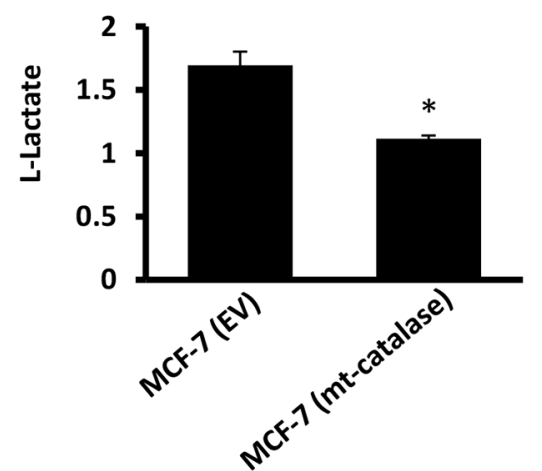

C.

Mitochondrial Potential

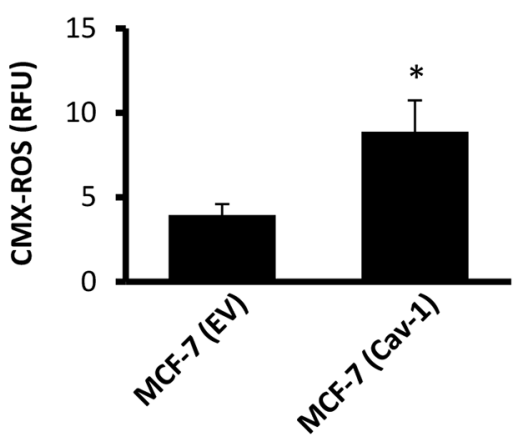

F.

Glycolysis

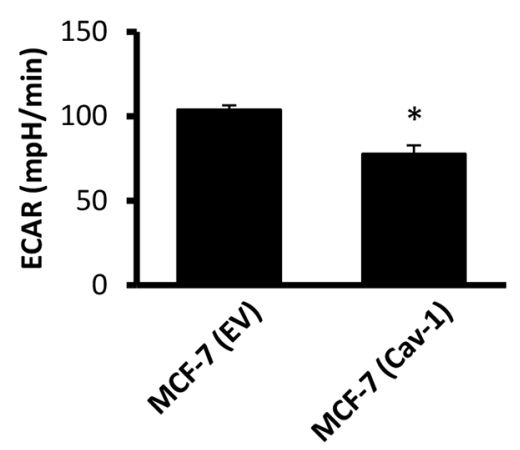

I.

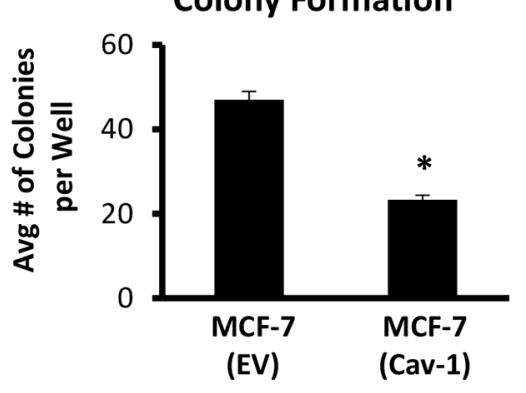

Figure 4: Cav-1 impedes AMPK-dependent glycolysis through inhibition of MnSOD-dependent $\mathrm{H}_{2} \mathrm{O}_{2}$. A. Western blot of MCF7 cells expressing empty vector (EV) or ectopic Cav-1 (Cav-1), in which Cav-1 expression reduces Nrf2 and MnSOD expression as well as AMPK activation as indicated by its active phosphorylation site Thr172. B. Nrf2 silencing in MCF7 cells (see methods) alone was sufficient to reduce MnSOD expression and AMPK activation. C. Cav-1 expression in MCF7 cells rescued mitochondrial potential as determined by CMX-ROS, in addition to restoring ATP production D. as measured by a luciferase-based ATP Determination Kit (Thermo Fisher Scientific). E. Cav-1 reconstitution in MCF7 cells increased mitochondrial respiration (OXPHOS as determined by basal OCR/ECAR), and F. reduced glycolytic metabolism (basal ECAR), in parallel measurement using Seahorse XF (Seahorse Bioscience). G. Transfection with mitochondriatargeted catalase (mt-catalase) was sufficient to impede AMPK activation (AMPK-T172) and H. reduced glycolysis as measured by L-lactate production determined by Cell-Based Glycolysis Assay Kit (Cayman). I. Cav-1 ectopic expression in MCF7 cells markedly reduced colony formation in soft agar, indicating a reduction of clonogenecity and anchorage-independent growth. (Student's two-sided $t$-test, $*=p<0.05$ ). 
to malignancy sets in motion Nrf2 activation and through it, MnSOD-driven metabolic reprogramming towards glycolysis. Tamoxifen-induced $\mathrm{v}$-Src expression in non-malignant $\mathrm{MCF} 10 \mathrm{~A}(\mathrm{Er} / \mathrm{Src})$ cells led to the rapid downregulation of Cav-1 expression. Cav-1 downregulation was progressive and preceded full transformation of $\mathrm{MCF} 10 \mathrm{~A}(\mathrm{Er} / \mathrm{Src})$ to a tumorigenic phenotype that has been reported to occur between $48-72 \mathrm{~h}$ following stimulation [32]. As shown in Figure 5A, Cav-1 levels were reduced $24 \mathrm{~h}$ after v-Src induction with peak suppression at $72 \mathrm{~h}$. Starting at $72 \mathrm{~h}, \mathrm{Cav}-1$ loss was accentuated by the loss of oligomers (previously reported to be the functional form of Cav-1 [5]). We also measured significantly increased MnSOD expression and AMPK activation particularly after $72 \mathrm{~h}$ following stimulation. Cav-1 loss in transforming cells was associated with the accumulation of Nrf2 in the nucleus as early as $48 \mathrm{~h}$ after induction of v-Src expression (Figure 5B and 5C). This enhancement in Nrf-2 nuclear localization was consistent with an increase in its stability in transformed MCF10A(Er/Src) cells (Figure 5D). In parallel with the increase in MnSOD expression and AMPK phosphorylation, steady state $\mathrm{H}_{2} \mathrm{O}_{2}$ levels progressively increased during v-Src-driven transformation (Figure 5E). The increase in $\mathrm{H}_{2} \mathrm{O}_{2}$ levels was in parallel with the shift from oxidative to glycolytic metabolism (Figure 5F and 5G). Taken together, these results demonstrate that the identified pathway of metabolic adaptation centered on MnSOD upregulation via Nrf2 is preceded by and dependent on Cav-1 degradation.

\section{Cav-1 loss is associated with MnSOD overexpression and $A M P K$ activation in an autochthonous mouse model of invasive breast carcinogenesis}

Next, we determined whether Cav-1 expression is reduced in mammary tumors of genetically modified mice constitutively expressing activated c-neu (ErbB2) gene (FVB-MMTV-ErbB2 [33]). As shown in Figure 6, immunostaining of Cav-1 in tissue sections obtained from healthy mammary glands of FVB controls as compared to mammary tumors from ErbB2 mice showed generalized reduction of Cav-1 expression in all ErbB2 mouse tumors analyzed, which also displayed elevated MnSOD expression and increased AMPK (Thr172) phosphorylation.

\section{DISCUSSION}

Our group has had a long-standing interest in the mechanistic underpinnings of the glycolytic switch in cancerous cells. Recently, we reported that the upregulation of MnSOD expression is required and sufficient for the metabolic reprogramming. Following this observation we sought to define molecular events that promote MnSOD expression in cancer. We found that Cav-1 protein levels in invasive ductal carcinoma are reduced early during tumor progression. Loss of Cav-1 expression is accentuated as tumors progress towards advanced and more aggressive stages (Figure 2). We also found that Cav-1 loss leads to an increased glycolytic activity that is imparted by MnSOD and its activation of AMPK via elevated $\mathrm{H}_{2} \mathrm{O}_{2}$ (Figure 5). These observations led us to hypothesize that the loss of Cav-1 is connected to the increase in MnSOD expression via Nrf2, a nuclear factor upstream of MnSOD that is scavenged by Cav-1. Here, we found that Nrf2 is, in fact, unleashed in Cav-1-deficient cells and that it indirectly enhances glycolysis in a manner dependent on the induction of MnSOD expression and MnSOD-derived $\mathrm{H}_{2} \mathrm{O}_{2}$. The findings of a mechanistic link between Cav-1 and MnSOD was reinforced by the analysis of existing epidemiologic data indicating that $\mathrm{Cav}-1^{\text {low }} / \mathrm{MnSOD}{ }^{\text {high }}$ represents a molecular signature consistent with that of glycolytic tumors that are typically more aggressive (Table 1). In fact, the reconstitution of Cav-1 expression in invasive MCF7 ductal carcinoma cells effectively reduced MnSOD expression and steady state $\mathrm{H}_{2} \mathrm{O}_{2}$ levels. Dampening $\mathrm{H}_{2} \mathrm{O}_{2}$, resulted in the preservation of Keap-1 and of its inhibitory association with Nrf2. Surprisingly, we also found that Cav-1 binds directly to both Nrf2 and Keap1 forming a ternary complex. In the absence of Cav-1 expression, significant Keap-1 oxidation was observed (Figure 3C). As shown before, oxidized Keap-1 dissociates from Nrf2 to promote its nuclear translocation and transcriptional activity [34-36]. This finding indicates that Cav-1 loss and oxidative stress collaborate to promote the disassembly of the $\mathrm{Nrf} 2 / \mathrm{Keap} 1$ complex thereby promoting the upregulation of MnSOD that leads to the glycolytic switch, as described previously [26]. It also supports the notion that the duration of oxidative stress can be determinant to elicit protective or pathologic functions of Nrf2. When transiently activated by spikes in $\mathrm{H}_{2} \mathrm{O}_{2}$ production, $\mathrm{Nrf} 2$ activates protective antioxidant defenses [8]; however, if persistently activated, Nrf2 leads to prolonged and marked enhancement of MnSOD expression that is sufficient to overcome antioxidant defenses and activate glycolysis, a form of metabolism permissive to malignant transformation. To further our mechanistic findings, a detailed analysis of Cav-1 and MnSOD expression was conducted using clinical samples (Figure 1). The results indicate that $\mathrm{Cav}-1$ expression is progressively reduced in breast cancer according to clinical stage and histologic grade and in aggressive breast cancer subtypes.

Consistently, we found that Cav-1 is strongly downregulated during induced malignant transformation. Cav-1 downregulation happened early after the induction of transformation by v-Src expression and was followed by increased Nrf2 stability and concomitant MnSOD upregulation, the enhancement in $\mathrm{H}_{2} \mathrm{O}_{2}$ production, AMPK activation, and to the activation of glycolysis. 


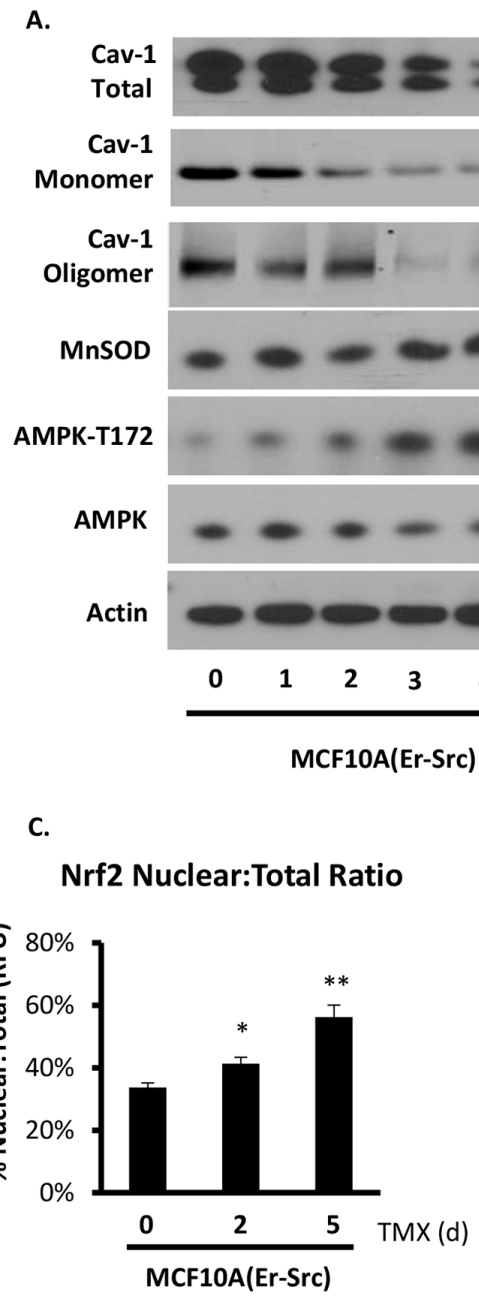

B.

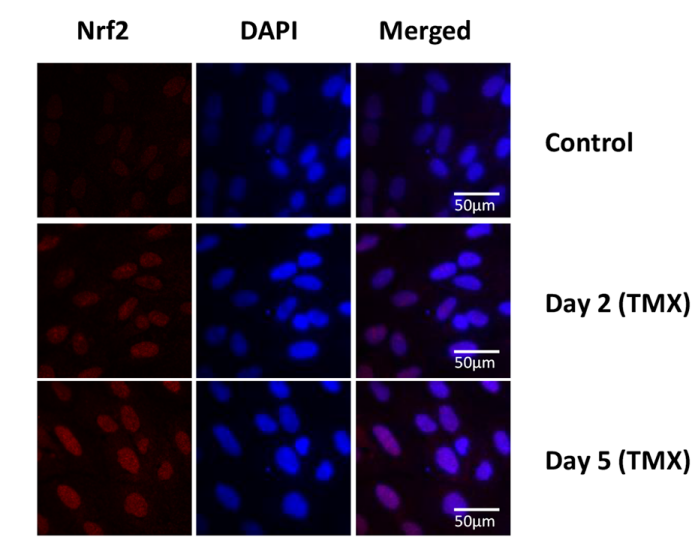

D.

Nrf2 stability

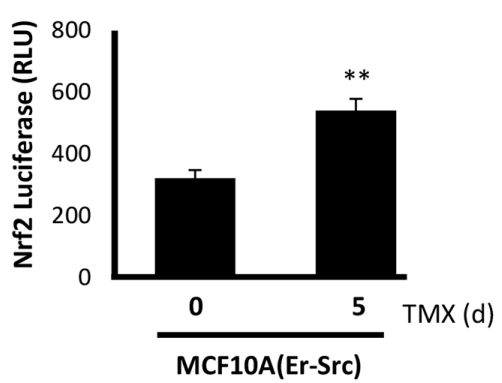

G. Glycolysis

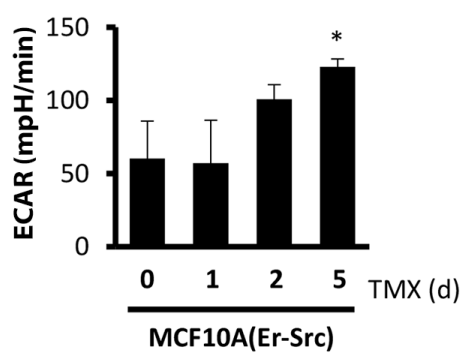

E.

$\mathrm{H}_{2} \mathrm{O}_{2}$ Production

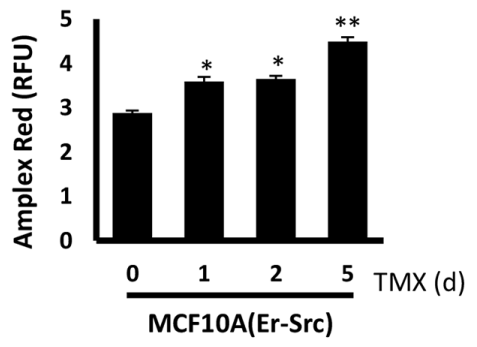

F. Basal OXPHOS

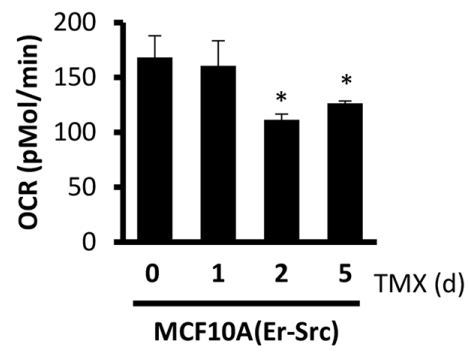

Figure 5: Cav-1 loss during malignant transformation is associated with increased Nrf2 activity and MnSOD upregulation that leads to AMPK-dependent glycolytic metabolism. MCF10A(Er/Src) cells were used to determine metabolic changes during malignant transformation. MCF10A(Er/Src) cells were treated with $1 \mu \mathrm{g} / \mathrm{mL}$ tamoxifen (TMX) for the times indicated. A. Cav-1 is reduced early in transformation (24 and $48 \mathrm{~h}$ ), followed by upregulation of MnSOD and AMPK activation (72 h), as determined by Western blot. Cav-1 oligomer/monomer distribution was assessed on the same non-reducing gel. B. Nrf2 nuclear localization is enhanced following Cav-1 loss at $48 \mathrm{~h}$ and is sustained following transformation. C. Quantification of the ratio of nuclear Nrf2 to total Nrf2 expression shows a predominant nuclear localization of Nrf2 during and following transformation. D. Quantification of Nrf2 stability suggests increased Nrf2 transcriptional activity in MCF10A( $\mathrm{Er} / \mathrm{Src})$ cells following transformation at 5 days post TMX induction. E. $\mathrm{H}_{2} \mathrm{O}_{2}$ production is increased as early as $24 \mathrm{~h}$ following TMX induction of v-Src and is significantly elevated following transformation at 96 and $120 \mathrm{~h}$, consistent with the high expression of MnSOD maintained after v-Src induced transformation. F. OXPHOS is reduced in $\mathrm{MCF} 10 \mathrm{~A}(\mathrm{Er} / \mathrm{Src})$ cells during and following transformation, and in parallel glycolysis is markedly increased following transformation G. (One-way ANOVA with post-hoc two-sided $t$-test, $*=p<0.05$, ** $=p<0.005$ ). 
A.
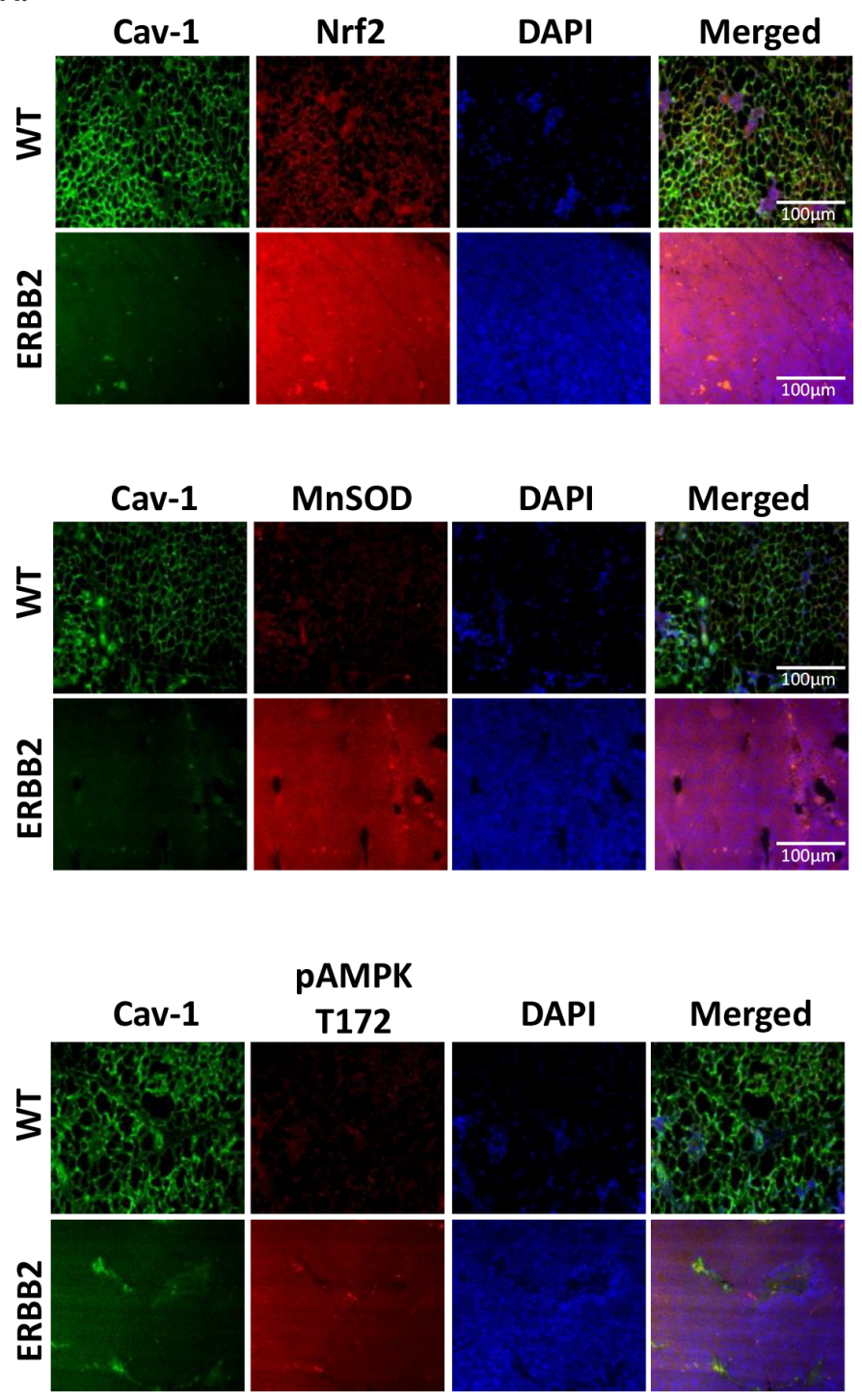

Figure 6: Cav-1 is repressed and MnSOD is increased in an in vivo model of malignancy. To investigate if Cav-1 may regulate MnSOD expression in an in vivo model of mammary tumor development, we used the FVB-(MMTV-ERBB2) mice, which express the activated ErbB2 (c-neu) gene and develop spontaneous mammary tumors within 9 months [33]. We observed that, compared to control FVB mice, ERBB2 mice demonstrated a ubiquitous loss of Cav-1 that was associated with increased expression of Nrf2 and MnSOD as well as increased activation of AMPK.

Together, our observations can be explained by a model in which the degradation of Cav-1 unleashes Nrf2 activity and the upregulation of MnSOD (see Figure 7). Upregulated MnSOD is a source of $\mathrm{H}_{2} \mathrm{O}_{2}$ that activates AMPK thereby inducing the glycolytic switch. In this regard, this study provides epidemiologic and mechanistic evidence indicating that the loss of Cav-1 expression promotes a form of metabolism that is permissive to breast cancer progression and, therefore, can negatively impact patient outcome. Based on the results reported here, we postulate that the levels of Cav-1 and MnSOD expression are determinant to metabolic changes that support tumor progression and that the Cav-1 $1^{\text {low/ }}$ $\mathrm{MnSOD}^{\text {high }}$ phenotype indicates a subgroup of aggressive types of breast cancer with poorer prognosis.

\section{MATERIALS AND METHODS}

\section{Cell culture}

Cell cultures of MCF7 cells stably expressing a myc-tagged empty vector (EV) or Cav-1 wild-type (Cav-1) were generated as described previously [37]. The cells were cultured in IMEM medium (Cellgro, Manassas, VA) supplemented with $10 \%$ fetal bovine serum (Atlanta Biologicals, Lawrenceville, GA) and 1\% penicillin/ streptomycin (Thermo Fisher Scientific Life Sciences, Grand Island NY). MCF10A(Er/Src) cells were a generous gift from Dr. Kevin Struhl (Harvard University). They were cultured as described in [38]. 

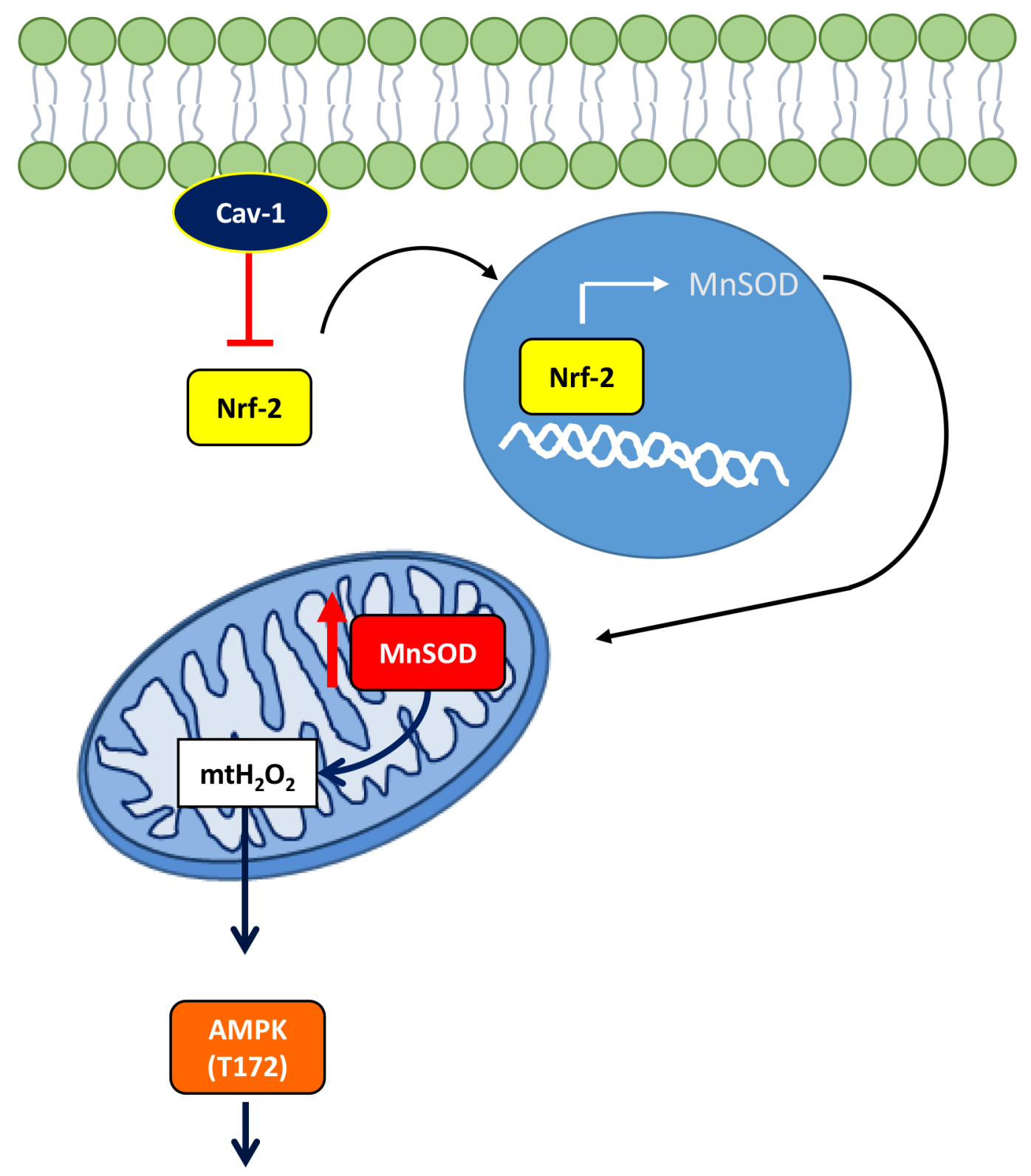

\section{Glycolysis}

Figure 7: Schematic: Cav-1 prevents Nrf2 dependent upregulation of MnSOD, thereby preventing the metabolic shift to glycolysis in breast cancer. Cav-1 prevents MnSOD overexpression in human breast cancer by suppression of Nrf2 transcriptional activity, thus reducing excess $\mathrm{mtH}_{2} \mathrm{O}_{2}$ regression from mitochondria and inhibiting downstream signaling events that bolster glycolysis.

\section{Mitochondrial-targeted catalase transfection}

Mitochondrial targeted catalase (Ad5-CMV-MTcatalase; mito-catalase) [39] was a generous gift from Dr. J. Andres Melendez (State University of New York at Albany). MCF7 cells were transfected with mito-catalase adenovirus by adding $1 \times 10^{6}$ infectious units to $80 \%$ confluent dishes, agitated every $15 \mathrm{~min}$ for $1 \mathrm{~h}$ at $37^{\circ} \mathrm{C}$, and then serum free media was added to prevent drying. After $6 \mathrm{~h}, 2 \mathrm{~mL}$ of complete media was added, and then changed to fresh media after $24 \mathrm{~h}$.

\section{Silencing of Nrf2 using siRNA}

To silence Nrf2 in MCF7 cells, siRNA specific for Nrf2 (Santa Cruz, Dallas, TX) was used. Briefly, cells were allowed to grow to $80 \%$ confluence and then treated with Nrf2-siRNA or scrambled-RNA using RNAiMAX (Thermo Fisher Scientific, Carlsbad, CA) in Opti-Mem (Thermo Fisher Scientific) according to the manufacturer's standard protocol. After $6 \mathrm{~h}$ media was increased to prevent drying, and at $24 \mathrm{~h}$ media was changed to complete media. Lysates for 
mito-catalase and Nrf2-siRNA were obtained at $72 \mathrm{~h}$ after transfection.

\section{Western blot analysis}

Protein lysates were separated on 4-12\% Bis-Tris gels and transferred to nitrocellulose membranes. The membranes were blocked for $60 \mathrm{~min}$ at room temperature in 5\% milk in TBS-T $(0.05 \%$ Tween- $20, \mathrm{pH} 7.4)$, washed with TBS-T and then incubated with primary antibody [rabbit anti-Cav-1 (Abcam, Cambridge, MA), mouse antiCav-1 ( BD Technologies, Research Triangle Park, NC), rabbit anti- $\beta$-actin (Cell Signaling Technologies, Boston, MA), rabbit anti-MnSOD(Abcam), rabbit anti-AMPK pThr-172 (Abcam), rabbit anti-Nrf2(Santa Cruz), mouse anti-Keap1 (Abcam), rabbit anti-Cysteine Sulfenic Acid (EMD Millipore, Billerica, MA)] in TBS-T overnight at $4^{\circ} \mathrm{C}$. Antibodies were diluted 1:1000 unless stated otherwise. After 3 washes, membranes were incubated with the infrared secondary antibody to anti-rabbit/mouse, 1:5,000 in TBS-T and incubated for 2 hours at room temperature. After 3 washes, protein signals were analyzed by Odyssey CLx Infrared Imaging System (LI-COR Biosciences, Lincoln, NE).

\section{Detection of cysteine oxidation and Keap1/Nrf2/ Cav-1 complex stability by immunoprecipitation}

Whole cell protein lysates were prepared from $90 \%$ confluent cell cultures in $100 \mathrm{~mm}$ culture dishes (Sigma, St. Louis, MO). Briefly, cell pellets were resuspended in $100 \mathrm{mM}$ 5,5-dimethylcyclohexane-1,3-dione (Dimedone, Sigma) and incubated at $37^{\circ} \mathrm{C}$ for 60 min under agitation. After washing with PBS, pellets were lysed in RIPA buffer (Cell Signaling) and then sonicated for 15 seconds using Sonic Dismembrator (ThermoFisher). Following sonication, supernatant was moved to a new tube and samples were incubated with $2 \mu \mathrm{g} / \mathrm{mL}$ primary antibody [mouse anti-Keap1, 1:100 (Abcam)] for $24 \mathrm{~h}$ at $4^{\circ} \mathrm{C}$. Magnetic beads [Dynabeads M-280 anti-mouse IgG (Thermo Fisher Scientific)] was then added and samples were incubated for 3 hours at $4^{\circ} \mathrm{C}$. After 3 washes, samples were analyzed by Western blotting as described above.

For co-immunoprecipitation of Cav-1/Keap1/Nrf2 complex, a direct immunoprecipitation method was used. Briefly, magnetic beads [Dynabeads M-280 antimouse or anti-rabbit IgG (Thermo Fisher Scientific)] were incubated with primary antibody [anti-rabbit Nrf2 1:100 (Santa Cruz) or anti-mouse Keap1 1:100 $\left(\right.$ Abcam)]) for $6 \mathrm{~h}$ at $4^{\circ} \mathrm{C}$. Beads were then washed to remove unbound primary antibody. Following treatment $\left(400 \mu \mathrm{M} \mathrm{H}_{2} \mathrm{O}_{2}, 1 \mathrm{~h}\right)$, cell lysates were added to the Dynabead/Antibody cocktail and incubated at $4^{\circ} \mathrm{C}$ overnight. Samples were washed twice with PBS and then analyzed by Western blot.

\section{Nrf2 luciferase assay}

Cells were grown to $80 \%$ confluence in 6 well dishes, and then co-transfected with pNLF1-NRF2[CMV/ neo] and pKeap1 according to manufacturer's protocol (Promega, Madison, WI) using Continuum Transfection Reagent (Gemini Bio-Products, Sacramento, CA). After 24 hours, cells were moved to 96-well white walled plates and incubated for an additional 48 hours. To determine Nrf2 reporter stability, Nano-Glo Luciferase Assay System (Promega) was used and luminescence was measured on a SpectraMax M5 spectrophotometer (Molecular Devices, Sunnyvale, CA). Measurements were then normalized to protein concentration measured through bicinchoninic acid (BCA) protein assay reagent (Thermo Fisher Scientific, Waltham, MA).

\section{Amplex red assay}

$\mathrm{H}_{2} \mathrm{O}_{2}$ production in cell culture was measured by Amplex Red Hydrogen Peroxide/Peroxidase Assay Kit (Thermo Fisher Scientific). Cells were grown to $80 \%$ confluence in a 6 -well plate, washed twice with PBS and then incubated with Amplex Red reaction buffer for $30 \mathrm{~min}$ at $37^{\circ} \mathrm{C}$. Amplex Red reaction buffer was then moved to a 96-well white walled plate and fluorescence was read at $560_{\mathrm{EX}} / 590_{\mathrm{EM}}$ on a SpectraMax M5 spectrophotometer (Molecular Devices) and normalized to protein concentration determined by BCA (Thermo Fisher Scientific).

\section{ATP assay}

Cells were grown in a 96-well white walled plate in standard media to $80 \%$ confluence. Media was replaced with glucose free media supplemented with galactose. Steady state ATP levels were measured using the luciferase based ATP determination kit (Thermo Fisher Scientific). ATP concentration in cell lysates was measured by luminescence on a SpectraMax M5 spectrophotometer (Molecular Devices) and normalized to protein concentration by BCA (Thermo Fisher Scientific).

\section{Glycolysis assay}

Cells were grown in 96-well clear plates in standard media to $80 \%$ confluence and Glycolysis CellBased Assay Kit (Cayman Chemical, Ann Arbor, MI) was performed according to manufacturer's instruction. Briefly, media was replaced with serum free media and incubated for $6 \mathrm{~h}$ at $37^{\circ} \mathrm{C}$. Supernatant (media) was moved to a 96-well plate and glycolysis reaction mix was added. Glycolysis was determined by L-lactate release into media which was read at 490nm absorbance on a SpectraMax M5 spectrophotometer (Molecular Devices) and then normalized to BCA (Thermo Fisher Scientific). 


\section{Mitochondrial respiration assay}

Cells were grown in Seahorse Bioscience (North Billerica, MA) plates as a monolayer at $80 \%$ confluence. Cells were then washed and left in Seahorse bicarbonate free media for 2 hours at $37^{\circ} \mathrm{C}$, then analyzed on the Seahorse Extracellular Flux (XFe24) Analyzer. The $\mathrm{XFe} 24$ Analyzer measures live cell oxygen consumption rate (OCR) and extracellular acidification rate (ECAR) in triplicate within intervals of $15 \mathrm{~min}$. Basal OCR is used as an indicator of mitochondrial respiration, and basal ECAR is used as an indicator of glycolysis. All measurements were standardized to cell count at seeding $\left(4 \times 10^{4}\right.$ cells $)$ and additionally normalized by BCA protein concentration (Thermo Fisher Scientific).

\section{Confocal microscopy}

Cells were plated and grown on confocal dishes (MatTek, Ashland, MA) in standard media to appropriate (60-80\%) confluence. Cells were then washed three times for $3 \mathrm{~min}$ with $1 \%$ PBS and fixated in $4 \%$ paraformaldehyde (Sigma) for $10 \mathrm{~min}$. Cells were washed three times in 1\% PBS for 3 min and permeabilized in $100 \%$ methanol for $15 \mathrm{~min}$. Cells were washed in $1 \%$ PBS three times for 3 min each and then blocked using $5 \%$ bovine serum albumin (BSA, Sigma) for $60 \mathrm{~min}$. Cells were then washed in $1 \%$ TBS-T three times for 3 min and incubated in primary antibodies [rabbit antiCav-1-1:100 (Abcam), mouse anti-Cav-1-1:100 (BD Technologies), rabbit anti-MnSOD- 1:100 (Abcam), goat anti-MnSOD-1:100 (Santa Cruz), rabbit anti-Nrf2-1:100 (Santa Cruz)] in 1\% BSA in $1 \%$ TBS-T overnight at $4^{\circ} \mathrm{C}$ in a humid chamber. Cells were washed three times in $1 \%$ TBS-T for $3 \mathrm{~min}$ and incubated with secondary fluorescent antibodies [rabbit Alexfluor-568, mouse Alexafluor-488 and goat Alexafluor-647 (Thermo Fisher Scientific)] for $2 \mathrm{~h}$ at room temperature in a dark, humid chamber. Cells were then washed three times in 1\% TBS-T for $3 \mathrm{~min}$ and incubated with $50 \mu \mathrm{M}$ DAPI (Thermo Fisher Scientific) for $30 \mathrm{~min}$. Cells were washed twice in 1\% TBS-T for $3 \mathrm{~min}$ and once in PBS for 5 min and then imaged using LSM510META (Carl Zeiss Microscopy, Thornwood, NY).

\section{Fluorescent immunohistochemistry}

Antigen retrieval was done using $10 \mathrm{mM}$ Sodium Citrate buffer at $20 \mathrm{psi}$ for $5 \mathrm{~min}$ in a Decloaking Chamber electric pressure cooker (Biocare Medical, Walnut Creek, CA). Slides were blocked with 10\% FBS for 45 min and incubated with primary antibody [rabbit antiCav-1-1:100 (Abcam), mouse anti-Cav-1-1:100 (BD Technologies), rabbit anti-MnSOD-1:100 (Abcam), goat anti-MnSOD-1:100 (Santa Cruz), rabbit anti-Nrf2-1:100 (Santa Cruz)] overnight at $4{ }^{\circ} \mathrm{C}$ in a humid chamber. Non-immune IgG was used for negative control. After rinsing in TBS-T, sections were incubated with secondary antibody [rabbit Alexfluor-568 and mouse Alexafluor-488 (Thermo Fisher Scientific)] for $2 \mathrm{~h}$ at room temperature in a dark, humid chamber. After incubating with $50 \mu \mathrm{M}$ DAPI, slides were mounted with FluoroMount Aqueous Solution (Sigma) and examined on an Apotome fluorescen microscope (Zeiss).

\section{Corrected total fluorescence}

Corrected total fluorescence was calculated as described previously [40]. Briefly, post-processing proceeded in ImageJ (National Institute of Health, Bethesda, MD) of each channel obtained during immunofluorescent acquisition of histological samples. Integrated density was used to measure total intensity (relative fluorescent units, RFU) within each selection of each channel, corrected against background mean grey value and area of measurement, and compiled across samples. Relative fluorescent units (RFU) as determined by corrected total fluorescence was calculated as follows: Integrated density of selection - (area of selection $\mathrm{x}$ mean background integrated density). Three background samples were taken per selection to assure proper calibration. Statistical analysis was performed as described below.

\section{Soft agar assay}

To evaluate clonogenecity and anchorageindependent growth, soft agar assay was performed. Briefly, $2 \times 10^{5}$ cells were seeded in 12 well dishes in $0.4 \%$ soft agar in native media on top of a layer of $0.8 \%$ soft agar (2X DMEM, 20\%FBS, 1\% Pen/Strep). Colonies were allowed to grow for 4 weeks, and then stained using Trypan Blue (Thermo Fisher Scientific). Colonies were imaged by EVOS Cell Imaging Systems (Thermo Fisher Scientific) and counted using ImageJ. Colonies were scored if at least 5 cells were present within one cluster.

\section{Epidemiology}

Data was obtained from the Oncomine ${ }^{\circledR}$ database (Compendia Bioscience, Ann Arbor, MI) using the SorlieBreast [27], Curtis-Breast [28] and Kao-Breast [29] datasets. Data and graphs were arranged in Microsoft Excel (Microsoft, Redmond, WA) and statistics were conducted using IBM SPSS Statistics 20 (IBM Corporation, Armonk, $\mathrm{NY}$ ). For odds ratio (OR) determination, binary/binomial logistic regression was performed using SPSS.

\section{Statistical analysis}

Statistical analysis was performed with GraphPad InStat. One-way ANOVA was performed with post-hoc Student-Newman-Keuls comparisons. A value of $P<0.05$ was considered significant whereas $a$ value of $P<0.01$ was considered highly significant. 


\section{ACKNOWLEDGMENTS AND FUNDING}

We would like to acknowledge funding from the U.S. Department of Defense, ARO \#61758-LS to M.G.B., UIC/Department of Medicine Innovators Fund/University of Illinois at Chicago to M.G.B.

\section{CONFLICTS OF INTEREST}

There are no conflicts to disclose.

\section{REFERENCES}

1. Lisanti MP, Scherer PE, Vidugiriene J, Tang Z, Hermanowski-Vosatka A, Tu YH, Cook RF and Sargiacomo M. Characterization of caveolin-rich membrane domains isolated from an endothelial-rich source: implications for human disease. J Cell Biol. 1994; 126:111-126.

2. Rothberg KG, Heuser JE, Donzell WC, Ying YS, Glenney JR and Anderson RG. Caveolin, a protein component of caveolae membrane coats. Cell. 1992; 68:673-682.

3. Lisanti MP, Scherer PE, Tang Z and Sargiacomo M. Caveolae, caveolin and caveolin-rich membrane domains: a signalling hypothesis. Trends Cell Biol. 1994; 4:231-235.

4. Schnitzer JE, Liu J and Oh P. Endothelial caveolae have the molecular transport machinery for vesicle budding, docking, and fusion including VAMP, NSF, SNAP, annexins, and GTPases. J Biol Chem. 1995; 270:14399-14404.

5. Sargiacomo M, Scherer PE, Tang Z, Kubler E, Song KS, Sanders MC and Lisanti MP. Oligomeric structure of caveolin: implications for caveolae membrane organization. Proc Natl Acad Sci U S A. 1995; 92:9407-9411.

6. Liu J, Oh P, Horner T, Rogers RA and Schnitzer JE. Organized endothelial cell surface signal transduction in caveolae distinct from glycosylphosphatidylinositol-anchored protein microdomains. J Biol Chem. 1997; 272:7211-7222.

7. Lu ML, Schneider MC, Zheng Y, Zhang X and Richie JP. Caveolin-1 interacts with androgen receptor. A positive modulator of androgen receptor mediated transactivation. J Biol Chem. 2001; 276:13442-13451.

8. Volonte D, Liu Z, Musille PM, Stoppani E, Wakabayashi N, Di YP, Lisanti MP, Kensler TW and Galbiati F. Inhibition of nuclear factor-erythroid 2-related factor (Nrf2) by caveolin-1 promotes stress-induced premature senescence. Molecular biology of the cell. 2013; 24:1852-1862.

9. Schlegel A, Wang C, Katzenellenbogen BS, Pestell RG and Lisanti MP. Caveolin-1 potentiates estrogen receptor alpha (ERalpha) signaling. caveolin-1 drives ligand-independent nuclear translocation and activation of ERalpha. J Biol Chem. 1999; 274:33551-33556.

10. Brouet A, Sonveaux P, Dessy C, Moniotte S, Balligand JL and Feron O. Hsp90 and caveolin are key targets for the proangiogenic nitric oxide-mediated effects of statins. Circ Res. 2001; 89:866-873.
11. Mao M, Varadarajan S, Fukai T, Bakhshi FR, Chernaya O, Dudley SC, Jr., Minshall RD and Bonini MG. Nitroglycerin tolerance in caveolin-1 deficient mice. PLoS One. 2014; 9:e104101.

12. Lim EJ, Smart EJ, Toborek M and Hennig B. The role of caveolin-1 in PCB77-induced eNOS phosphorylation in human-derived endothelial cells. Am J Physiol Heart Circ Physiol. 2007; 293:H3340-3347.

13. Majkova Z, Toborek M and Hennig B. The role of caveolae in endothelial cell dysfunction with a focus on nutrition and environmental toxicants. J Cell Mol Med. 2010; 14:2359-2370.

14. Isshiki M, Ando J, Yamamoto K, Fujita T, Ying Y and Anderson RG. Sites of $\mathrm{Ca}(2+)$ wave initiation move with caveolae to the trailing edge of migrating cells. J Cell Sci. 2002; 115:475-484.

15. Grande-Garcia A, Echarri A, de Rooij J, Alderson NB, Waterman-Storer CM, Valdivielso JM and del Pozo MA. Caveolin-1 regulates cell polarization and directional migration through Src kinase and Rho GTPases. J Cell Biol. 2007; 177:683-694.

16. Bakhshi FR, Mao M, Shajahan AN, Piegeler T, Chen Z, Chernaya O, Sharma T, Elliott WM, Szulcek R, Bogaard HJ, Comhair S, Erzurum S, van Nieuw Amerongen GP, et al. Nitrosation-dependent caveolin 1 phosphorylation, ubiquitination, and degradation and its association with idiopathic pulmonary arterial hypertension. Pulm Circ. 2013; 3:816-830.

17. Yang KC, Rutledge CA, Mao M, Bakhshi FR, Xie A, Liu H, Bonini MG, Patel HH, Minshall RD and Dudley SC, Jr. Caveolin-1 modulates cardiac gap junction homeostasis and arrhythmogenecity by regulating cSrc tyrosine kinase. Circ Arrhythm Electrophysiol. 2014; 7:701-710.

18. Bitar MS, Abdel-Halim SM and Al-Mulla F. Caveolin-1/ PTRF upregulation constitutes a mechanism for mediating p53-induced cellular senescence: implications for evidencebased therapy of delayed wound healing in diabetes. Am J Physiol Endocrinol Metab. 2013; 305:E951-963.

19. Pavlides S, Tsirigos A, Vera I, Flomenberg N, Frank PG, Casimiro MC, Wang C, Fortina P, Addya S, Pestell RG, Martinez-Outschoorn UE, Sotgia F and Lisanti MP. Loss of stromal caveolin-1 leads to oxidative stress, mimics hypoxia and drives inflammation in the tumor microenvironment, conferring the "reverse Warburg effect": a transcriptional informatics analysis with validation. Cell Cycle. 2010; 9:2201-2219.

20. Chanvorachote $\mathrm{P}$ and Chunhacha P. Caveolin-1 regulates endothelial adhesion of lung cancer cells via reactive oxygen species-dependent mechanism. PLoS One. 2013; 8:e57466.

21. Simpkins SA, Hanby AM, Holliday DL and Speirs V. Clinical and functional significance of loss of caveolin-1 expression in breast cancer-associated fibroblasts. J Pathol. 2012; 227:490-498. 
22. Pavlides S, Whitaker-Menezes D, Castello-Cros R, Flomenberg N, Witkiewicz AK, Frank PG, Casimiro MC, Wang C, Fortina P, Addya S, Pestell RG, MartinezOutschoorn UE, Sotgia F, et al. The reverse Warburg effect: aerobic glycolysis in cancer associated fibroblasts and the tumor stroma. Cell Cycle. 2009; 8:3984-4001.

23. Cerezo A, Guadamillas MC, Goetz JG, Sanchez-Perales S, Klein E, Assoian RK and del Pozo MA. The absence of caveolin-1 increases proliferation and anchorage- independent growth by a Rac-dependent, Erk-independent mechanism. Mol Cell Biol. 2009; 29:5046-5059.

24. Hulit J, Bash T, Fu M, Galbiati F, Albanese C, Sage DR, Schlegel A, Zhurinsky J, Shtutman M, Ben-Ze'ev A, Lisanti MP and Pestell RG. The cyclin D1 gene is transcriptionally repressed by caveolin-1. J Biol Chem. 2000; 275:21203-21209.

25. Burgermeister E, Friedrich T, Hitkova I, Regel I, Einwachter H, Zimmermann W, Rocken C, Perren A, Wright MB, Schmid RM, Seger R and Ebert MP. The Ras inhibitors caveolin-1 and docking protein 1 activate peroxisome proliferator-activated receptor gamma through spatial relocalization at helix 7 of its ligand-binding domain. Mol Cell Biol. 2011; 31:3497-3510.

26. Hart PC, Mao, M., Abreu, A.L., Ansenberger-Fricano, K., Ekou, D.N., Ganini, D., Kajdacsy-Balla, A., Diamond, A.M., Minshall, R.D., Consolaro, M.E., Santos, J.H., Bonini, M.G. MnSOD upregulation sustains the Warburg effect via mitochondrial ROS and AMPK-dependent signalling in cancer. Nat Commun. 2015; 6:6053.

27. Sorlie T, Perou CM, Tibshirani R, Aas T, Geisler S, Johnsen H, Hastie T, Eisen MB, van de Rijn M, Jeffrey SS, Thorsen T, Quist H, Matese JC, et al. Gene expression patterns of breast carcinomas distinguish tumor subclasses with clinical implications. Proc Natl Acad Sci U S A. 2001; 98:10869-10874.

28. Curtis C, Shah SP, Chin SF, Turashvili G, Rueda OM, Dunning MJ, Speed D, Lynch AG, Samarajiwa S, Yuan Y, Graf S, Ha G, Haffari G, et al. The genomic and transcriptomic architecture of 2,000 breast tumours reveals novel subgroups. Nature. 2012; 486:346-352.

29. Kao KJ, Chang KM, Hsu HC and Huang AT. Correlation of microarray-based breast cancer molecular subtypes and clinical outcomes: implications for treatment optimization. BMC Cancer. 2011; 11:143.

30. Li W, Liu H, Zhou JS, Cao JF, Zhou XB, Choi AM, Chen $\mathrm{ZH}$ and Shen HH. Caveolin-1 inhibits expression of antioxidant enzymes through direct interaction with nuclear erythroid 2 p45-related factor-2 (Nrf2). The Journal of biological chemistry. 2012; 287:20922-20930.

31. Kansanen E, Kuosmanen SM, Leinonen H and Levonen AL. The Keap1-Nrf2 pathway: Mechanisms of activation and dysregulation in cancer. Redox Biol. 2013; 1:45-49.

32. Iliopoulos D, Hirsch HA and Struhl K. An epigenetic switch involving NF-kappaB, Lin28, Let-7 MicroRNA, and IL6 links inflammation to cell transformation. Cell. 2009; 139:693-706.

33. Peng M, Ball-Kell SM, Franks RR, Xie H and Tyner AL. Protein tyrosine kinase 6 regulates mammary gland tumorigenesis in mouse models. Oncogenesis. 2013; 2:e81.

34. Itoh K, Wakabayashi N, Katoh Y, Ishii T, Igarashi K, Engel JD and Yamamoto M. Keap1 represses nuclear activation of antioxidant responsive elements by Nrf2 through binding to the amino-terminal Neh2 domain. Genes Dev. 1999; 13:76-86.

35. Dhakshinamoorthy $\mathrm{S}$ and Jaiswal AK. Functional characterization and role of INrf2 in antioxidant response element-mediated expression and antioxidant induction of $\mathrm{NAD}(\mathrm{P}) \mathrm{H}$ :quinone oxidoreductase1 gene. Oncogene. 2001; 20:3906-3917.

36. Fourquet S, Guerois R, Biard D and Toledano MB. Activation of NRF2 by nitrosative agents and $\mathrm{H} 2 \mathrm{O} 2$ involves KEAP1 disulfide formation. J Biol Chem. 2010; 285:8463-8471.

37. Shajahan AN, Dobbin ZC, Hickman FE, Dakshanamurthy S and Clarke R. Tyrosine-phosphorylated caveolin-1 (Tyr-14) increases sensitivity to paclitaxel by inhibiting BCL2 and BCLxL proteins via c-Jun N-terminal kinase (JNK). J Biol Chem. 2012; 287:17682-17692.

38. Hirsch HA, Iliopoulos D, Joshi A, Zhang Y, Jaeger SA, Bulyk M, Tsichlis PN, Shirley Liu X and Struhl K. A transcriptional signature and common gene networks link cancer with lipid metabolism and diverse human diseases. Cancer Cell. 2010; 17:348-361.

39. Rodriguez AM, Carrico PM, Mazurkiewicz JE and Melendez JA. Mitochondrial or cytosolic catalase reverses the MnSOD-dependent inhibition of proliferation by enhancing respiratory chain activity, net ATP production, and decreasing the steady state levels of $\mathrm{H}(2) \mathrm{O}(2)$. Free Radic Biol Med. 2000; 29:801-813.

40. Burgess A, Vigneron S, Brioudes E, Labbe JC, Lorca T and Castro A. Loss of human Greatwall results in G2 arrest and multiple mitotic defects due to deregulation of the cyclin B-Cdc2/PP2A balance. Proc Natl Acad Sci U S A. 2010; 107:12564-12569. 